\title{
Evaluation of the Prevalence of Incidental HBV, HCV and HIV Infection Among Patients Presenting to the Emergency Department: A Prospective Cross-sectional Study
}

\author{
(D) Mehmet Murat Oktay ${ }^{1}$, (D) Behçet Al², (D) Yasemin Zer ${ }^{3}$, (D) Cuma Kılıçoğlu ${ }^{4}$, (D) Mustafa Boğan ${ }^{5}$, (D) Mustafa Sabak ${ }^{6}$, \\ (D) Hasan Gümüșboğa7 \\ ${ }^{1}$ Vocational High School, Hasan Kalyoncu University, Gaziantep, Turkey \\ 2Emergency Department of Medicine Faculty, Gaziantep University, Gaziantep, Turkey \\ ${ }^{3}$ Microbiology and Clinical Microbiology Department of Medicine Faculty, Gaziantep University, Gaziantep, Turkey \\ ${ }^{4}$ Emergeny Clinic of Balıklıgöl State Hospital, Sanlıurfa, Turkey \\ ${ }^{5}$ Emergency Department of Medicine Faculty, Düzce University, Düzce, Turkey \\ ${ }^{6}$ Emergency Clinic of Nizip State Hospital, Gaziantep, Turkey \\ ${ }^{7}$ Emergency Clinic of Șehitkamil State Hospital, Gaziantep,Turkey
}

\begin{abstract}
Aim: In this study, we randomized the patients without known hepatitis-B, hepatitis $\mathrm{C}$ and HIV infection who presented to the emergency department (ED). We measured the serum levels of HBsAg, Anti-HCV and Anti-HIV antibodies besides biochemical tests regarding the diagnostic process of the main complaint resulting in presentation to the ED. In this way, we aimed to determine the prevalence of occult chronic viral diseases among patients presenting to the ED and the risk of ED employees was evaluated.

Materials and Methods: The study included 800 patients who had presented to the ED for any reason over two month and who had no history of infectious viral disease.

Results: Four hundred and thirthy-four (54.2\%) of the patients were male, $366(45.8 \%)$ were female, and the mean age was $32.7( \pm 16.9)$ years. The rate of presence of a person with an infectious viral disease at the patient's home was $1 \%, 0.5 \%$ and $0.0 \%$ for HBV, HCV, and HIV, respectively. The overall history of $\mathrm{HBV}$ vaccination was $15.5 \%$ in our study sample. HBsAg, anti-HCV and HIV-positivity were $2 \%, 0.8 \%$ and $0.0 \%$, respectively.

Conclusion: The prevalence of HBV- and HCV-positivity in patients admitted to the ED who did not have any known chronic viral disease was consistent with the general population prevalence. No significant change in the prevalence of HCV compared to previous years can be explained by the absence of a protective vaccine. The absence of HIV-positivity can be explained by the low rate of HIV-positivity in our country.
\end{abstract}

Keywords: Emergency medicine, HBV, HCV, HIV, chronic viral diseases

\section{INTRODUCTION}

According to the World Health Organization (WHO) data in 2017, it is estimated that more than 2 billion people are infected with the Hepatitis B Virus (HBV) around the world and 257 million people have chronic HBV infection. Most of the 887,000 deaths resulting from hepatitis B infection in 2015 were due to complications such as cirrhosis and hepatocellular carcinoma (HCC) (1).

HBV infection is usually acquired in adulthood. Transmission through sexual contact and parenteral drug use with shared needles in adolescents and young adulthood has been identified as the most important transmission route. However, perinatal 
or early childhood infections also pose a great risk for the development of HBV infection (2). Many epidemiological and molecular studies have shown that chronic HBV infection is the main risk factor for the development of HCC. Chronic HBV infection is seen in approximately $5 \%$ of infections seen in adults, whereas, this rate accounts for $90 \%$ in neonatal infections. Although HBV generally does not cause direct cytopathic effects in hepatocytes, it is thought to induce hepatic damage (fibrosis, cirrhosis, and $\mathrm{HCC}$ ) as a result of persistent immune reaction and inflammation in the liver (3). The European Center for Disease Prevention and Control has reported the prevalence of HBV infection among the general population in Turkey as 2-8\% by September 2010 (4).

Hepatitis C Virus (HCV) spreads predominantly through blood and blood contamination, such as drug injection. Furthermore, HCV outbreaks have been linked to non-sterile medical practices, unprotected blood transfusions and sexual transmission (5-9). Around two hundred million people (3\% of the whole population) are infected with HCV worldwide. Approximately three to four million new cases are seen each year, and more than 350,000 people die each year due to diseases caused by HCV infection. There is very little data about the genetic properties and regional distribution of HCV infection in Turkey (7).

According to the 2018 data of the United Nations AIDS Unit, it is reported that approximately 36.9 million people are infected with Human Immunodeficiency Virus (HIV) worldwide and 53.1\% (19.6 million) of them live in sub-Saharan Africa. As of 2017, the number of people receiving antiretroviral treatment reached 19 million and the mortality rate decreased by $34 \%$. According to the 2016 data in our country, a total of 14695 HIV infected/AIDS cases were reported $(10,11)$.

Previous studies have shown that the rate of contact of emergency service providers with the blood, blood products and body fluids of patients admitted to the emergency department is rather high. Similarly, the incidence of occupational exposure to blood or other body fluids is higher among Emergency Department (ED) workers than in the general public officials (12-16). This situation increases the risk of transmission of HBV, HCV and HIV infection among health care providers in ED. In this study, we aimed to conduct a risk analysis for ED health workers due to the patients who presented to the ED without a history of HBV, HCV or HIV infection.

\section{Materials and Methods}

The study was approved by the Gaziantep University Faculty of Medicine Ethics Committee for Clinical Studies (approval date: 12.09.2018, decision no: 2018/211) and carried out in the Department of Emergency Medicine at Sahinbey Research and Practice Hospital. The study was conducted following the Declaration of Helsinki and an informed consent form was signed by each participant before blood samples were drawn. Health care is provided to approximately $180,000-210,000$ patients annually in the afore-mentioned ED. A total of 44,720 patients had presented to our ED during the two months of the study.

A total of 800 patients who had presented to the Adult ED with any complaint between 01.10.2018 and 01.12.2018 and who fulfilled the study criteria were randomly recruited. To provide randomization in the study, the resident on duty included the first patient who presented at his/her shift every hour and who fulfilled the study criteria and gave written consent.

Pre-prepared forms for the study included the patients' age, gender, medical history, history of regular drug use, surgical interventions (including curettage and superficial abscess drainage), alcohol or drug/stimulant use, blood replacement history, presence of individuals with infectious viral diseases (HBV, HCV, HIV) in their domestic environment, and the HBV vaccination history was recorded.

The exclusion criteria; patients with a history of HBV, HCV or HIV infection, those younger than 16 years, and those who refused to participate voluntarily were excluded from the study.

The inclusion criteria and workflow; Patients older than 16 years of age presenting to our ED for any reason at any time of the day and who did not know whether or not they were infected with HBV, HCV or HIV were included in the study. In addition to the laboratory samples examined in the diagnostic process of patients who fulfilled the study criteria, 3 ccs of extra blood samples were collected for the measurement of serum HBsAg, anti-HCV and antiHIV antibody levels and sent to the Microbiology Laboratory of Sahinbey Research and Practice Hospital. The blood samples were transferred to the BD Vacutainer ${ }^{\circledR}$ SSTTM II Advance (REF 367955) biochemistry tubes containing gel and taken to the laboratory within 5 minutes. The samples were recorded in the medical automation system and centrifuged in the laboratory at $4000 \mathrm{rpm}$ for 5 minutes. The serum on top of the precipitate was removed and examined using the Abbott $^{\circledR}$ kits on the Architect 2000 SR $^{\circledR}$ (ELISA) device. Blood samples that were not examined immediately were separated by centrifugation and stored at -20 oC for a maximum of 2 days and then examined in the same way. The device used for analysis works according to the Macro ELIZA principle.

The number of samples was calculated by considering the study with the highest rate (8\%) in our country and WHO data averages (3\%) (3). We use the internationally recognized formula in the calculation as follows: 
$\left.\mathrm{N} 1=\left\{\mathrm{z}_{1}-\alpha / 2 \pm \sqrt{\mathrm{p}^{-} * \mathrm{q} *\left(1+\frac{1}{\mathrm{k}}\right)}+\mathrm{z}_{1}-\beta \times \sqrt{\mathrm{p}_{1} * \mathrm{q}_{1}+\left(\mathrm{p}_{2}\right.}+\mathrm{q}_{2}\right)\right\}^{2} / \Delta^{2}$

Based on the assumption that the study was in the 85\% confidence interval when the values were used in this formulation,

$\mathrm{N}_{1}=\left\{1,96 * \sqrt{0,055 \times 0,945 *\left(1-\frac{1}{1}\right)}+1.04+\sqrt{0,08+0,92+\left(\frac{0.013 \cdot 1,57}{1}\right)}\right\}^{2 / 0.05^{2}}$

$\mathrm{N} 1=372, \mathrm{~N}_{2}=\mathrm{k} \times \mathrm{N}_{1}=372$, Total $\mathrm{n}=744$ number of participants (sample size) was calculated. Thus, we recruited a total of 800 subjects.

\section{Statistical Analysis}

The data of the patients were recorded at a computer file and analyzed with the SPSS 23.0 program. A chi-square test was used to analyze the relationship between two categorical variables; the t-test was used to compare the dependent variables. A p value of less than 0.05 was considered statistically significant.

\section{Results}

Of the 44,720 patients presenting to our emergency department during the two-month study period, 21,500 (48.08\%) were male and 23,320 (51.92\%) were female and the mean age was $34.74 \pm 16.80$ years. Of the 800 patients who were recruited in the study, 434 (54.2\%) were male, 366 (45.2\%) were female and the mean age was $37.7 \pm 16.8$ years. $58.4 \%$ of the patients were within the $16-35$ age category (Table 1$)$.

Among eight hundred patients, incidental HBV-positivity and HCV-positivity were $16(2 \%)$ and six (0.8\%), respectively. None of the patients had HBV and HCV coexistence. No incidental HIVpositive patients were determined. HBV-positivity was dominant in females and HCV-positivity in males (Table 2).

Of the patients included in the study, 23.3\% (186) reported having a chronic disease. Among these 186 patients, HBV-positivity was determined in six (3.2\%) and HCV-positivity in one (0.5\%). There was no statistically significant relationship between the presence of chronic disease and HBV-positivity $(p=0.173)$ or HCV-positivity $(p=0.702)$ (Table 3).

Of 175 patients (21.9\%) who reported chronic drug use, six (3.4\%) had HBV-positivity and one (0.6\%) had HCV-positivity. The relationship between chronic drug use and HBV-positivity $(p=0.127)$ or HCV-positivity $(p=0.757)$ was not statistically significant (Table 3).

One hundred and thirthy patients (16.3\%) stated that they had undergone a surgical operation previously. HBV was positive in three $(2.3 \%)$ and HCV was positive in one $(0.8 \%)$ of them. There was no statistically significant relationship between a previous surgical operation history and HBV-positivity $(p=0.784)$ or HCVpositivity ( $p=0.978$ ) (Table 3).

None of the patients reported chronic alcohol or stimulant/drug use. However, $8 \%(n=64)$ of the participants defined themselves as "social drinkers". HBV-positivity $(p=0.794)$ was found in one (1.6\%) and HCV-positivity ( $p=0.022)$ in two $(3.1 \%)$ of 64 patients who stated that they were social drinkers (Table 3).

Forty-five (5.6\%) patients reported that they had previously undergone blood transfusion for any reason. HBV-positivity was found in one (2.2\%) $(p=0.913)$ and HCV-positivity was found in two $(4.4 \%)(p=0.003)$ of these 45 patients (Table 3$)$.

When we questioned the presence of an individual with the infectious viral disease in his/her domestic environment, eight (1\%) subjects reported that there was an HBV-positive person at home. One of these eight (12.5\%) was HBV-positive $(p=0.160)$. Four $(0.5 \%)$ subjects reported that there was an HCV-positive person at home. HCV was positive in one of these four $(25 \%)$ $(p=0.001)$ (Table 3). None of the participants reported that there was an HIV-positive person at home.

A total of 124 subjects (15.5\%) declared that they had been vaccinated against HBV. Sixty-one (7.6\%) of them were male and 63 (7.9\%) were female. There were no patients among those undergoing HBV vaccination, who had a concomitant HBV infection.

\begin{tabular}{|l|l|l|l|}
\hline \multicolumn{4}{|l|}{ Table 1. Age Groups and gender distribution of patients } \\
\hline Age category, (year) & Male & Female & Total, n (\%) \\
\hline $16-25$ & 109 & 110 & $219(27.5 \%)$ \\
\hline $26-35$ & 142 & 106 & $248(30.9 \%)$ \\
\hline $36-45$ & 73 & 58 & $131(16.4 \%)$ \\
\hline $46-55$ & 35 & 32 & $67(8.3 \%)$ \\
\hline $56-65$ & 27 & 21 & $48(6.0 \%)$ \\
\hline+66 & 48 & 39 & $87(10.9 \%)$ \\
\hline Total & $434(54.2 \%)$ & $366(45.8 \%)$ & $800(100 \%)$ \\
\hline
\end{tabular}

Table 2. Presence of HBV and HCV infection and gender distribution of patients

\begin{tabular}{|l|l|l|l|l|}
\hline \multicolumn{2}{|c|}{} & Male & Female & Total \\
\hline \multirow{3}{*}{ HBV } & Positive (+) & $\mathbf{7}$ & $\mathbf{9}$ & $\mathbf{1 6}$ \\
\cline { 2 - 5 } & Negative (-) & 427 & 357 & 784 \\
\cline { 2 - 5 } & Total & 434 & 366 & 800 \\
\hline \multirow{2}{*}{ HCV } & Positive (+) & $\mathbf{4}$ & $\mathbf{2}$ & $\mathbf{6}$ \\
\cline { 2 - 5 } & Negative (-) & 430 & 364 & 794 \\
\hline & Total & 434 & 366 & 800 \\
\hline
\end{tabular}


Table 3. The Relationship between HBV/HCV positivity and patient characteristics

\begin{tabular}{|c|c|c|c|c|c|}
\hline & Total patients & $\mathrm{HBV}+$ & $\mathrm{p}$ value & $\mathrm{HCV}+$ & $\mathrm{p}$ value \\
\hline Presence of chronic illness & 186 & 6 & 0.173 & 1 & 0.702 \\
\hline Regular drug intake & 175 & 6 & 0.127 & 1 & 0.757 \\
\hline Past surgery history & 130 & 3 & 0.784 & 1 & 0.978 \\
\hline Alcohol intake & 64 & 1 & 0.794 & 2 & $0.022^{*}$ \\
\hline Blood transfusion history & 45 & 1 & 0.913 & 2 & $0.003^{*}$ \\
\hline Presence of a virally infected person in the domestic environment & 64 & 1 & 0.160 & 2 & $0.001^{*}$ \\
\hline
\end{tabular}

\section{Discussion}

It is reasonable to say that studies conducted in emergency services in our country can be considered as an indicator of the general prevalence of the population in epidemiological studies due to the high number of participants.

HBV infection shows significant racial/ethnic and geographic differences regarding viral exposure and immunity. In the United States, the overall prevalence of chronic HBV infection in the general population is $0.34 \%$, which is more common among Asians and the black population (17). The European continent is a low endemic region for HBV infection. The overall prevalence of HBV is about $0.9 \%$ in EU countries. The number of cases with chronic HBV infection is estimated to be approximately 4.7 million in Europe (18). Chronic HBV infection is thought to be highly endemic in the overall African continent. In Asia, both high and low-risk countries have been reported regarding HBV infection. The rate of the population with chronic HBV infection has been reported to be $2-4 \%$ in Japan, $5-18 \%$ in China, $15-20 \%$ in Taiwan, and $2-7 \%$ in Iran (19-22). The prevalence of chronic HBV infection was found as 4-5\% in Turkey in 2007 and it was reported to be $4.57 \%$ in a meta-analysis published in 2011 (23-24). Similarly, HBV-positivity was calculated as $4 \%$ in another study population by Tozun et al. (25). In our study, the incidental HBV-positivity prevalence was calculated as 2\% (16 patients). When the results of our study were compared with previous studies in our country, a lower prevalence rate was found. We believe that the success of routine HBV vaccination, which was launched in 1998 in Turkey, has a great contribution to this decline. Similarly, in Taiwan (26), China (27) and Poland (28), the incidence of HBsAg-positivity has been shown to decrease after initiation of routine nationwide $H B V$ vaccination program. We believe that the inclusion of the $H B V$ vaccine in the routine vaccination programs is an important factor in decreasing the prevalence of HBV worldwide.

Studies reporting the prevalence of HCV have demonstrated significant geographical and regional differences in the epidemiology of HCV infection in Europe. In general, the prevalence of HCV is between $0.1-1 \%$ in northern Europe, 0.2-1.2\% in Central Europe and 2.5-3.5\% in southern Europe (29). Among the continents, the estimated prevalence is lowest in Northern Europe where the prevalence of HCV was reported to be lower than 1\%; its prevalence is high in countries in North Asia and Africa. The lowest HCV prevalence was reported in the UK and the Scandinavian countries (less than 1\%); the highest prevalence was reported from Egypt (15-20\%) $(30,31)$. In our country, the epidemiological data for HCV are mostly obtained from local studies, and anti-HCV positivity has been reported between 0.1$1.5 \%$ in community-based studies $(23,32,33)$. The best estimate of the prevalence of HCV in our country is approximately $1 \%$ (33). In our study, the rate of anti-HCV-positive patients was $0.8 \%$. Our results are consistent with other studies conducted in our country.

The HIV prevalence in Turkey was found to be $0.019 \%$ in 2016 (10). However, there were no HIV-positive patients determined in our study. Due to the extremely low incidence and the relatively small sample size of our study, the absence of HIV-positive patients was considered to be normal in our results.

Of the 45 patients (5.6\%) who declared that they had received blood transfusion for any reason in our study, one (2.2\%) had HBV-positivity $(p=0.913)$ and two (4.4\%) had HCV-positivity $(p=0.003)$. Blood transfusion is an important route of viral transmission in developing countries. In developed countries, transmission through blood transfusions has decreased considerably. For example, the risk of HCV transmission is estimated to be approximately 0.52 per million donations in the US, 0.70 in Canada, and between 0.1 and 2.33 in different European countries (33-35). According to our results, HCV transmission among patients receiving blood transfusion is quite high compared to the rates in developed countries. However, in our study, it is not possible to attribute the cause of transmission to blood transfusion alone in these patients. In our study, two (33\%) of six HCV positive patients were over 50 years of age. In the literature, some studies show the relationship between HCV positivity and the patient's age. However, we did not reach such 
a conclusion in our study. In a study conducted by Niu et al. (34) on 2685 patients in China, the distribution of patients was examined by age and the rate of those older than 50 years was found to be $59.33 \%$. In our country, some studies are examining the age-specific prevalence of HCV showing that the prevalence of HCV increases with age, especially after the age of 50 years $(25,30)$. The results of our study were not consistent with the afore-mentioned studies in the literature in terms of age and HCV-positivity. In our study, the number of patients with HCV was only six, which did not allow the comparison of the HCV prevalence under and above 50 years of age.

In our study, the relationship between the presence of an HCVpositive person at home and HCV-positivity was statistically significant. Some studies in the literature have reported similar results. Anti-HCV-positivity was determined in $20.5 \%$ of people living with an HCV-positive person at home in a study evaluating domestic HCV transmission in Pakistan, while another study in Egypt reported 18\% anti-HCV-positivity (36-38). In our study, four (0.5\%) subjects declared to live with an HCV-positive individual at home. HCV-positivity was determined in one (25\%) of these four people. Our result was statistically significant $[(p=0.001)$ (Table 3)] and supports previous studies. In particular, educating people living with HBV, HCV and HIV-positive individuals at their homes regarding the transmission routes of the disease would be effective in reducing the transmission rates.

\section{Study Limitations}

As the sociocultural structure of our society is taken into consideration, it is highly likely to provide incomplete or misleading information on alcohol and drug/substance use, since only the patients' declaration was based in our study. For the same reason, although suspicious sexual intercourse is an important route of transmission, which can explain unknown reasons, the fact that it could not be questioned has created a significant limitation in our study. Since there were no HIVpositive patients in our study, no detailed analysis could be performed.

\section{Conclusion}

Emergency departments are units to which a large number of and all kinds of patients present and the necessary interventions are required without waiting for the results of biochemical analyses. Emergency Medicine Specialists and other ED employees are at high risk of exposure to blood-borne pathogens in these intensive settings. Although the incidence of $\mathrm{HBV} / \mathrm{HCV} / \mathrm{HIV}$ infection appears to be low in our study, health workers should comply fully with personal protection methods due to the high risk of transmission.
In our study, the rate of those who declared the presence of HBV vaccination was found to be $15.5 \%$ among 800 patients. Increasing the vaccination rates and performing them properly will decrease the prevalence of HBV infection to lower rates in our country.

The lack of a significant decrease in the prevalence of HCV in our country over the years reveals the importance of vaccination development studies. The lack of an effective vaccine yet can be seen as one of the main reasons why the desired success in combating the disease has not been achieved. However, it is possible to decrease the rate of transmission by increasing social awareness.

We believe that the publication of a large number of news and visual materials in the media regarding HIV infection results in a high level of awareness of the disease in our country. The registration and follow-up of the digital medical file system by the Ministry of Health is quite successful for HIV infection and AIDS. Although the number of patients is low in our country, it is very important for public health that the fight against HIV is not interrupted.

\section{Ethics}

Ethics Committee Approval: Ethics committee approval was taken from Gaziantep University Faculty of Medicine Ethics Committee for Clinical Studies (approval date: 12.09.2018, decision no: 2018/211).

Informed Consent: Informed consent forms were signed by each participant before blood samples were drawn.

Peer-review: Externally and internally peer-reviewed.

\section{Authorship Contributions}

Concept: B.A., Y.Z., Design: B.A., M.M.O., Data Collection or Processing: C.K., H.G., M.M.O., M.S. Analysis or Interpretation: B.A., Y.Z., Literature Search: M.M.O., M.S., Writing: M.M.O., M.S., M.B.

Conflict of Interest: The authors declared no potential conflicts of interest with respect to the research, authorship, and/or publication of this article.

Financial Disclosure: The authors received no financial support for the research, authorship, and/or publication of this article.

\section{References}

1. World Health Organization Progress Reports 2018 http://www.who.int/ mediacentre/factsheets/fs204/en/ (Accessed: 06/04/2019).

2. Alabaz D. Çocuklarda Kronik Hepatit B Tedavisi. Alhan E (Editör). Çocukluk Çağında Viral Hepatitler. İstanbul; Medya Tower Tanıtım ve Yayıncılık, 2007. p45-50.

3. Schuppan D, Afdhal NH. Liver cirrhosis. The Lancet; 2008;371:838-51.

4. European Centre for Disease Prevention and Control. Systematic review on hepatitis B and C prevalence in the EU/EEA. Stockholm: ECDC; 2016. 
5. Magiorkinis G, Magiorkinis E, Paraskevis D, Ho SY, Shapiro B, Pybus OG, et al. The global spread of hepatitis $C$ virus $1 \mathrm{a}$ and $1 \mathrm{~b}$ : a phylodynamic and phylogeographic analysis. PLoS medicine. 2009;6:e1000198.

6. Sunbul M, Khan A, Kurbanov F, Leblebicioglu H, Sugiyama M, Tanaka Y, et al. Tracing the spread of hepatitis C virus in Turkey: a phylogenetic analysis. Intervirology. 2013;56:201-5.

7. Afsar I, Gungor S, Sener AG, Yurtsever SG. The prevalence of HBV, HCV and HIV infections among blood donors in Izmir, Turkey. Indian journal of medical microbiology. 2008;26:288.

8. Lampe E, Espirito-Santo MP, Martins RM, Bello G. Epidemic history of Hepatitis C virus in Brazil. Infection, Genetics and Evolution. 2010;10:886-95.

9. Hajarizadeh B, Grebely J, Dore GJ. Epidemiology and natural history of HCV infection. Nature reviews Gastroenterology \& hepatology. 2013;10:553.

10. WHO Global HIV Report 2016. https://www.who.int/hiv/pub/arv/global-aidsupdate-2016-pub/en/ (Accessed: 06/04/2019).

11. Tümer A. HIV/AIDS nedir? (2019). http://www.hatam.hacettepe.edu.tr/AIDS_ web-2019.pdf (Accessed: 06/04/2019).

12. Van Wijk PT, Pelk-Jorgen M, De Boer E, Voss A, Wijkmans C, Schneeberger PM. Differences between hospital-and community-acquired blood exposure incidents revealed by a regional expert counseling center. Infection. 2006;34:17-21.

13. Averhoff FM, Moyer LA, Woodruff BA, Deladisma AM, Nunnery J, Alter MJ, et al. Occupational exposures and risk of hepatitis virus infection among public safety workers. J Occup Environ Med. 2002;44:591-6.

14. Gershon RMR, Sherman M, Mitchell C, Vlahov D, Erwin MJ, Lears MK, et al. Prevalence and risk factors for bloodborne exposure and infection in correctional healthcare workers. Infect Control Hosp Epidemiol. 2007;28:2430.

15. Lorentz J, Hill L, Samimi B. Occupational needlestick injuries in a metropolitan police force. Am J Prevent Med. 2000;18:146-50.

16. Pagane J, Chanmugam A, Kirsch T, Kelen GD. New York City Police Officers incidence of transcutaneous exposures. Occup Med (Lond). 1996; 46:285-8.

17. Rosner B. Fundamentals of Biostatistics. 7th ed. Boston, MA: Brooks/Cole; 2011.

18. Kim HS, Rotundo L, Yang JD, Kim D, Kothari N, Feurdean M, et al. Racial/ ethnic disparities in the prevalence and awareness of Hepatitis B virus infection and immunity in the United States. Journal of viral hepatitis. 2017; 24:1052-66.

19. Zampino R, Boemio A, Sagnelli C, Alessio L, Adinolfi LE, Sagnelli E, et al. Hepatitis B virus burden in developing countries. World journal of gastroenterology. 2015;21:11941.

20. Tun W, Vu L, Adebajo SB, Abiodun L, Sheehy M, Karlyn A, et al. Populationbased prevalence of hepatitis B and C virus, HIV, syphilis, gonorrhoea and chlamydia in male injection drug users in Lagos, Nigeria. International journal of STD \& AIDS. 2013;24:619-25.

21. Chen CJ, Wang LY, Yu MW. Epidemiology of hepatitis B virus infection in the Asia-Pacific region. Journal of gastroenterology and hepatology. 2000;15:E3E6.
22. Poorolajal J, Majdzadeh R. Prevalence of chronic hepatitis B infection in Iran: a review article. Journal of research in medical sciences: the official journal of Isfahan University of Medical Sciences. 2009;14:249.

23. Mistık R. The epidemiology of viral hepatitis in Turkey. Analysis of published data. Viral hepatitis. Ankara: Association of Viral Hepatitis. 2007;18:10-50.

24. Toy M. Age- and region-specific hepatitis B prevalence in Turkey estimated using generalized linear mixed models: a systematic review. BMC Infectious Diseases. 2011;11:1

25. Tozun N, Ozdogan O, Cakaloglu Y, Idilman R, Karasu Z, Akarca U, et al. Seroprevalence of hepatitis $B$ and $C$ virus infections and risk factors in Turkey: a fieldwork TURHEP study. Clinical Microbiology and Infection. 2015;21:1020-6

26. Ni YH, Chang MH, Huang LM. Hepatitis B Virus Infection in Children and Adolescents in a Hyperendemic Area: 15 Years after Mass Hepatitis B Vaccination. Annals Internal Medicine. 2001;135:796-800.

27. Luo Z, Li L, Ruan B. Impact of the implementation of a vaccination strategy on hepatitis B virus infections in China over a 20-year period. International Journal of Infectious Disaeses. 2012;16:82-8.

28. Magdzik W. Hepatitis B epidemiology in Poland, Central and Eastern Europe and the newly independent states. Vaccine. 2000;18:13-6.

29. Esteban JI, Sauleda S, Quer J. The changing epidemiology of hepatitis C virus infection in Europe. J Hepatol. 2008;48:148-62.

30. Bahap M. Hepatit B ve C Virüsü ile Enfekte Hastaların Tedavisinde Ilaç Kaynaklı Sorunlar (Master's thesis, Sağlık Bilimleri Enstitüsü). Ankara; Hacattepe University. 2018. http://www.openaccess.hacettepe.edu.tr:8080/xmlui/ bitstream/handle/11655/4802/10209106. pdf?sequence=1\&isAllowed =y

31. Kayman T, Karakükçü Ç, Karaman A, Gözütok F. Kayseri bölgesinde Hepatit $C$ virüs enfeksiyonunun genotip dağılımı. Türk Mikrobiyol Cem Derg. 2012;42:21-6.

32. Dursun M, Ozekinci T, Ertem M, Saka G, Yilmaz S, Canoruc F, et al. Prevalence of hepatitis $\mathrm{C}$ in adults in the south-eastern region of Anatolia: a communitybased study. Hepatol Res. 2004;29:75-80.

33. Akcam FZ, Uskun E, Avsar K, Songur Y. Hepatitis B virus and hepatitis C virus seroprevalence in rural areas of the South-western region of Turkey. Int J Infect Dis. 2009;13:274-84.

34. Niu Z, Zhang P, Tong Y. Age and gender distribution of Hepatitis C virus prevalence and genotypes of individuals of physical examination in WuHan, Central China. Springerplus. 2016;5:1557.

35. Moradpour D, Blum HE. A primer on the molecular virology of hepatitis C. Liver International. 2004;24:519-25.

36. Shadid I. Hepatitis C Virus Infection Treatment: Recent Advances and New Paradigms in the Treatment Strategies. 2017;285-308.

37. Wyles DL. Antiviral resistance and the future landscape of hepatitis C virus infection therapy. The Journal of infectious diseases. 2013;207:S33-S9.

38. Nakano T, Lau GM, Lau GM, Sugiyama M, Mizokami M. An updated analysis of hepatitis C virus genotypes and subtypes based on the complete coding region. Liver international. 2012;32:339-45. 